\title{
Gross and Histo-Pathological Changes in Japanese Quail (Coturnix Coturnix Japonica) Experimentally Infected with Salmonella Enterica Serovar Gallinarum
}

\author{
Barde Israel Joshua ${ }^{1,}$, , Bale James Olaniyi Olabode ${ }^{2}$, Oladele Sunday Blessing ${ }^{2}$, \\ Fatihu Mohammed Yakassai ${ }^{2}$, Kumbish Peterside Rinle ${ }^{1}$, Chukwu Doris Isioma ${ }^{1}$, \\ Rimfa Amos Gambo", Akanbi Babatunde Olatunde ${ }^{1}$, Moses Gyang Davou ${ }^{1}$, Ahmed James Saidu ${ }^{1}$, \\ Okewole Philip Ademola ${ }^{1}$
}

${ }^{1}$ Department of Central Diagnostic Laboratory, National Veterinary Research Institute, Plateau State, Nigeria
${ }^{2}$ Department of Veterinary Pathology, Ahmadu Bello University, Zaria, Kaduna State, Nigeria

Email address:

israelbarde@yahoo.com (B. I. Joshua)

\section{To cite this article:}

Barde Israel Joshua, Bale James Olaniyi Olabode, Oladele Sunday Blessing, Fatihu Mohammed Yakassai, Kumbish Peterside Rinle, Chukwu Doris Isioma, Rimfa Amos Gambo, Akanbi Babatunde Olatunde, Moses Gyang Davou, Ahmed James Saidu, Okewole Philip Ademola. Gross and Histo-Pathological Changes in Japanese Quail (Coturnix Coturnix Japonica) Experimentally Infected with Salmonella Enterica Serovar Gallinarum. Animal and Veterinary Sciences. Vol. 3, No. 3, 2015, pp. 84-88. doi: 10.11648/j.avs.20150303.12

\begin{abstract}
A total of 160 (108 males and 52 females) Japanese quails (Coturnix coturnix japonica) were used for the experiment. The quails were obtained at the age of four weeks from the Poultry Division of the National Veterinary Research Institute (NVRI), Vom, Plateau State, Nigeria. They were randomly selected and assigned into four groups (A, B, C and D) of forty quails each. Groups A, B and C were infected with Salmonella enterica serovar Gallinarum per os at the dose of $10^{6}$, $10^{4}$ and $10^{2}$, respectively, while group D served as the control. Mortality rate ranged from $30 \%$ to $35 \%$. Grossly, congestion of the liver, lung and ovarian follicle were generally observed in all the infected groups. Also bronzed liver, hepato-splenomegaly, swollen and congested kidney and ascites were observed. Histopathological lesions included; congestion and cellular infiltration of various organs (liver, lung and heart), as well as hepatic vacuolation and hemorrhages. The high mortality rate, gross and histo-pathological findings in this study demonstrate that Japanese quails (Coturnix coturnix japonica) are highly susceptible to Salmonella enterica serovar Gallinarum.
\end{abstract}

Keywords: Gross-Histopathology, Japanese- Quail, Salmonella Gallinarum

\section{Introduction}

The genus Salmonella is a member of the Family Enterobacteriaceae and consists of Gram-negative, non-spore forming bacilli (Popoff et al., 2003).Salmonella enterica serovar Gallinarum (Salmonella Gallinarum) is a non-motile host adaptive Salmonella that causes fowl typhoid (FT), a severe systemic disease responsible for heavy economic losses to the commercial poultry industry through morbidity, mortality and pathological lesions (Parmer and Davies, 2007).With the continuous expansion of poultry farming in Nigeria, FT has become endemic in poultry resulting in heavy economic losses through mortality and pathogical lesions (Agbaje et al., 2010). Quails are ideally suited for avian research, because of their small size and require little cage space for rearing. They are easy to raise and are suitable for genetic studies since they rapidly attain sexual maturity (Haruna et al., 1997). Quails are hardy birds which thrive very well in cages and are relatively inexpensive to maintain. They are birds that every household can keep without stress (Huss et al., 2008).Although quail farming contributes to the alleviation of protein- deficiency in the diets of people in developing countries, they have largely been neglected as a livestock species due to their small size. Most farmers have focused mainly on chicken production. Thus, the potential contributions of quail to food production have been greatly ignored and or underestimated by policy makers in the agricultural sector in these countries. Nigerians are interested in quail production especially for medicinal reasons and so quail farming should be encouraged with a special focus on the 
traditional subsistence rearing system as practiced by resourcelimited farmers (NVRI, 2008).

There is a scarcity of information on microscopic lesions of FT in chickens and quails, and most of the lesions described are from field cases which may be complicated by other bacterial and or viral agents in chickens and to a lesser extent quails (Chadfield et al., 2003).Japanese quails have received less attention relative to other poultry species by researchers (Agrey et al., 2003).The Japanese quail has the potential of filling the gap in the protein needs of Nigerians, it is therefore important to investigate diseases that can interfere with production such as FT in order to determine effective control measures. Quail meat and eggs are known for high quality protein, high biological value and low caloric value, thus making them good choices for hypertension prone individuals (NVRI, 2008).

This study evaluated the gross and histopathological changes in Japanese quail (Coturnix coturnix japonica)infected with Salmonella enterica serovar Gallinarum (Salmonella Gallinarum)in Zaria, Kaduna State , Nigeria.

\section{Methodology}

\subsection{Area of Study}

The study was carried out in Zaria, Kaduna State, which is located within the Northern Guinea Savannah Zone of Nigeria, between latitude $7^{\circ}$ and $11^{\circ} \mathrm{N}$, and longitude $7^{\circ}$ and $44^{\circ} \mathrm{E}$. The average rainfall of this zone ranges from 1,000 to $1,250 \mathrm{~mm}$ annually, and the average temperature ranges from $17^{\circ} \mathrm{C}$ to $33^{\circ} \mathrm{C}$ (Saidu et al., 1994).

\subsection{Experimental Birds}

A total of 160, four-week old Japanese quails (108 males and 52 females) were obtained from the Poultry Division of National Veterinary Research Institute, Vom, Nigeria and used for the experiment. They were randomly selected and divided into four groups (A, B, C and D) of 40 birds each; with 27 males and 13 females in group A, 23 males and 17 females in group B, 29 males and 11 females in group C as well as group D.

\subsection{Housing and Feeding}

The quails were allowed to acclimatize for two weeks. The quails were kept in mesh cages of $120 \times 140 \times 120 \mathrm{~cm}$ in size in an enclosed house with the litter changed every week throughout the experimental period.The quails were fed for two weeks on commercial chick mash, after which they were fed commercial layer mash throughout the remaining period of the research which lasted 120 days. They were fed and provided with water ad libitum during this period.

\subsection{Bacteriological Monitoring Before Infection}

Before infection, cloacal swabs were collected from all the quails in order to confirm if they were free from Salmonella organism. This was done by pre-enrichment of the swab samples in buffered peptone water, followed by plating on MacConkey agar (MCA) and blood agar (BA) using standard laboratory methods (Parmer and Davies, 2007).

\subsection{Source of Organism and Infectivity Procedure}

The bacterium, Salmonella enterica serovar Gallinarum, was obtained from the bacterial culture bank of the Central Diagnostic Laboratory, National Veterinary Research Institute, Vom, Nigeria. The Salmonella isolate was from a day old chick that died from a natural infection of Salmonella Gallinarum. The lyophilized bacterium from the culture bank was reactivated by sub-culturing on blood agar (BA) and MacConkey agar (MCA). The resulting colonies were examined for their features, colour and morphology and tested for Gram-reaction (Gram-negative). Three colonies were scooped and inoculated into $20 \mathrm{ml}$ of nutrient broth and incubated for 24 hours at $37 \mathrm{oC}$ after which a ten-fold dilution was carried out in test tubes. The colony counts from the test tubes were determined. To obtain the number of organisms that were inoculated into the quails, the number of organisms was multiplied by volume and by the dilution factor (CFU= No. of colony $\times$ Volume $\times$ Reciprocal of Dilution factor) (Miles and Misra, 1938). Challenge of the quails was done orally using sterile syringes.Group A quails received a dose of $1 \times 10^{6}$ organisms $/ 0.2 \mathrm{ml}$ of nutrient broth, group B quails received a dose of $1 \times 10^{4}$ organisms $/ 0.2 \mathrm{ml}$ of nutrient broth, while group $\mathrm{C}$ quails received a dose of $1 \times 10^{2}$ organisms $/ 0.2 \mathrm{ml}$ of nutrient broth.Group D served as control and were not challenged with the bacterium, but were given bacteria-free nutrient broth in accordance with the method of Miles and Misra (1938).

\subsection{Pathological Examinations}

Mortality was recorded. A detailed post-mortem examination was performed on dead birds, and on birds surviving to the end of the experiment, following euthanasia by cervical dislocation. Gross lesions were observed, recorded and photographed. Samples of the liver, spleen, heart, small and large intestines, lung, ovary, pancreas and caecal tonsil showing gross lesions werecollected and fixed in $10 \%$ buffered neutral formalin for at least 48 hours. Following fixation, the tissues were trimmed, placed in cassettes and dehydrated in graded concentrations of alcohol (70\%, 80\%, 90\% and 100\%) using an automatic tissue processor (STP 120). The tissues were cleared with xylene, embedded in molten paraffin wax block and labelled appropriately (Oladele et al., 2008).The tissue paraffin blocks were sectioned at $5 \mu \mathrm{m}$ thick, using a microtome. The sectioned tissues were mounted on a grease-free, clean glass slide, dried at room temperature and stained with haematoxylin and eosin $(\mathrm{H} \& \mathrm{E})$ stains. The slides were evaluated using light microscope at $\times 40$ and $\times 100$ magnifications in order to determine any pathological changes. Photomicrographs of lesions from the different organs were taken, transferred to a computer and labelled 
appropriately (Hossain et al., 2006).

\section{Results and Discussion}

Mortality was observed in all infected groups (A, B and C), with mortality rates of $35 \%, 30 \%$ and $30 \%$, respectively (Table 1). No mortality was recorded in group D (control).

Table 1. Mortality pattern of Japanese quails after infection with Salmonella enterica serovar Gallinarum.

\begin{tabular}{lllll}
\hline \multirow{2}{*}{ Day after infection } & \multicolumn{2}{l}{ Mortality rate per group } & & Group D (control) \\
\cline { 2 - 5 } & Group A $\left(\mathbf{1 0}^{\mathbf{6}}\right)$ & Group B $\left(\mathbf{1 0}^{4}\right)$ & Group C (10 $)$ & - \\
\hline 5 & 3 & - & - & - \\
7 & 4 & 3 & 3 & - \\
8 & 3 & 3 & 3 & - \\
9 & 2 & 1 & 2 & - \\
10 & 1 & 2 & 1 & - \\
11 & 1 & 1 & 1 & - \\
15 & - & 1 & - & - \\
18 & - & 1 & 1 & - \\
\hline
\end{tabular}

Table 2. Gross lesions in different groups of quails experimentally infected with Salmonella enterica serovar Gallinarum.

\begin{tabular}{|c|c|c|c|c|}
\hline \multicolumn{5}{|c|}{ Number and percentage of birds with lesions in each infected group } \\
\hline \multicolumn{5}{|c|}{ Group } \\
\hline Organ/Lesion & $A\left(10^{6}\right)$ & B $\left(10^{4)}\right.$ & $\mathbf{C}\left(10^{2}\right)$ & D (control) \\
\hline \multicolumn{5}{|l|}{ Liver } \\
\hline Hepatomegaly & $5(12.5 \%)$ & $5(12.5 \%)$ & $4(10 \%)$ & 0 \\
\hline Congestion & $19(47.5 \%)$ & $26(65 \%)$ & $17(42.5 \%)$ & 0 \\
\hline Bronze discoloration & $2(5 \%)$ & $1(2.5 \%)$ & $1(2.5 \%)$ & 0 \\
\hline Friable & - & - & $2(5 \%)$ & 0 \\
\hline \multicolumn{5}{|l|}{ Lung } \\
\hline Congestion & $19(47.5 \%)$ & $26(65 \%)$ & $17(42.5 \%)$ & 0 \\
\hline Edema & $3(7.5 \%)$ & $6(15 \%)$ & $5(12.5 \%)$ & 0 \\
\hline \multicolumn{5}{|l|}{ Spleen } \\
\hline Spleenomegaly & $6(15 \%)$ & $4(10 \%)$ & $3(7.5 \%)$ & 0 \\
\hline \multicolumn{5}{|l|}{ Kidney } \\
\hline Swelling & - & $1(2.5 \%)$ & - & 0 \\
\hline \multicolumn{5}{|l|}{ Ovarian Follicle } \\
\hline Egg yolk peritonitis & $1(2.5 \%)$ & $1(2.5 \%)$ & - & 0 \\
\hline Congestion & $1(2.5 \%)$ & $2(5 \%)$ & $1(2.5 \%)$ & 0 \\
\hline \multicolumn{5}{|l|}{ Peritoneum } \\
\hline Hydroperitoneum (ascites) & $1(2.5 \%)$ & - & - & 0 \\
\hline
\end{tabular}

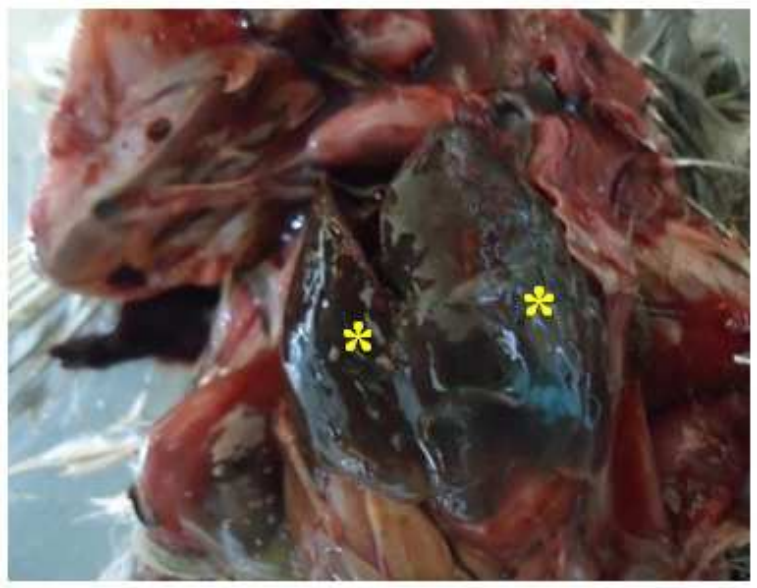

Plate I. Japanese quail (Coturnix coturnix japonica) experimentally infected with $10^{4}$ of Salmonella enterica serovar Gallinarum.Note hepatomegaly and bronze liver (*)

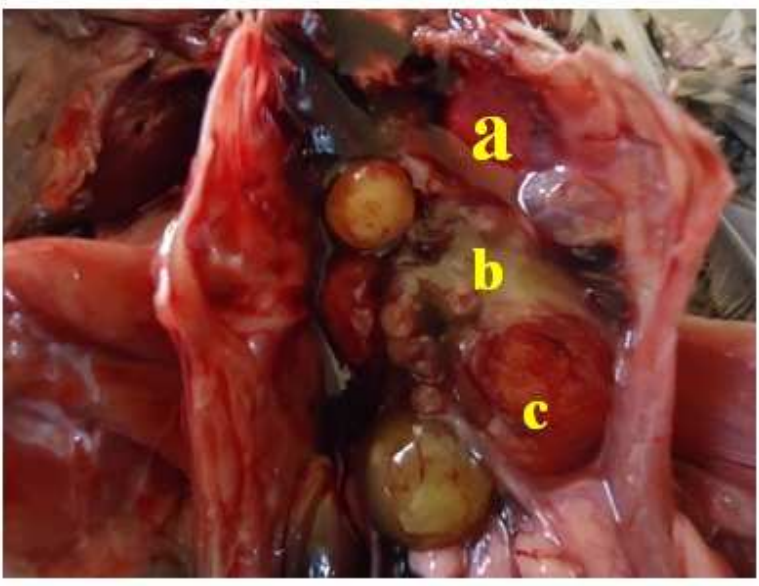

Plate II. Japanese quail (Coturnix coturnix japonica) experimentally infected with $10^{6}$ of Salmonella enterica serovar Gallinarum. Note congested lung (a), egg yolk peritonitis (b) and congested ovarian follicle (c). 


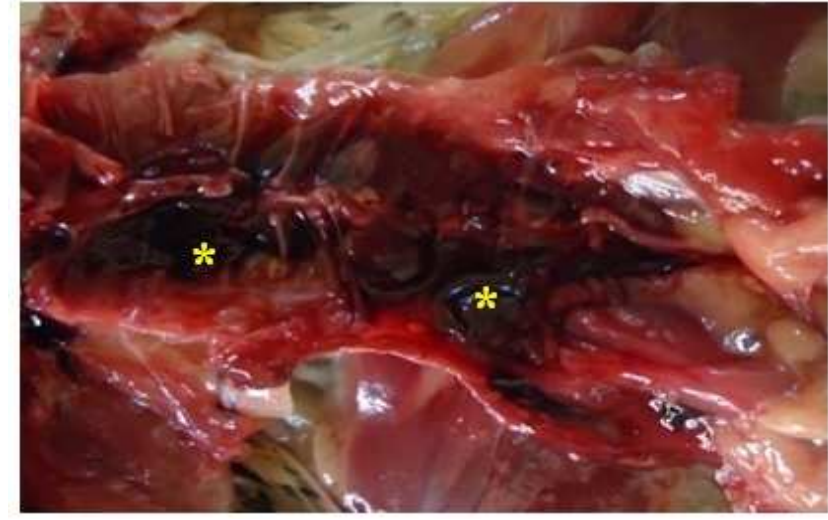

Plate III. Japanese quail (Coturnix coturnix japonica) experimentally infected with $10^{6}$ of Salmonella enterica serovar Gallinarum. Note enlarged and congested kidneys (*).

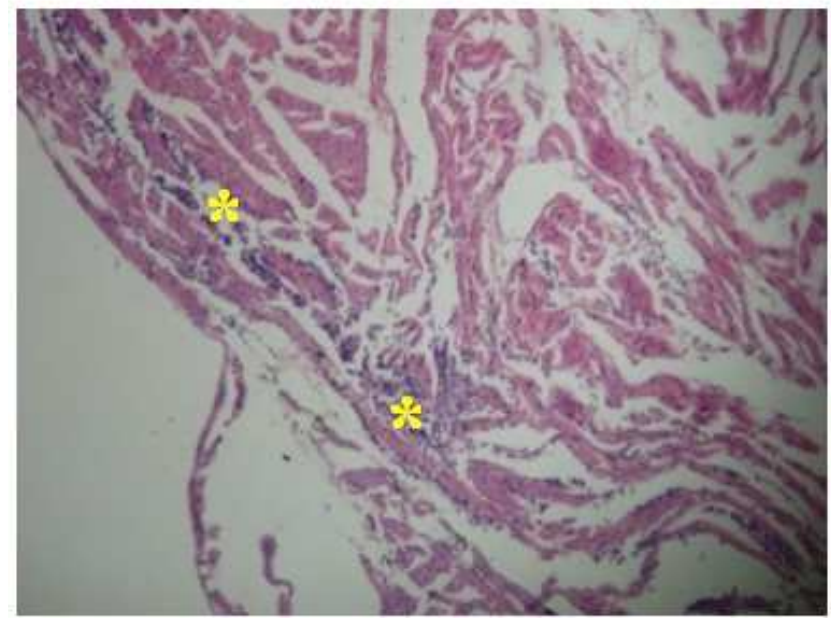

Plate IV. Photomicrograph of the heart of Japanese quail (Coturnix coturnix japonica) experimentally infected with $10^{6}$ of Salmonella enterica serovar Gallinarum Note: Generalized cellular infiltration.

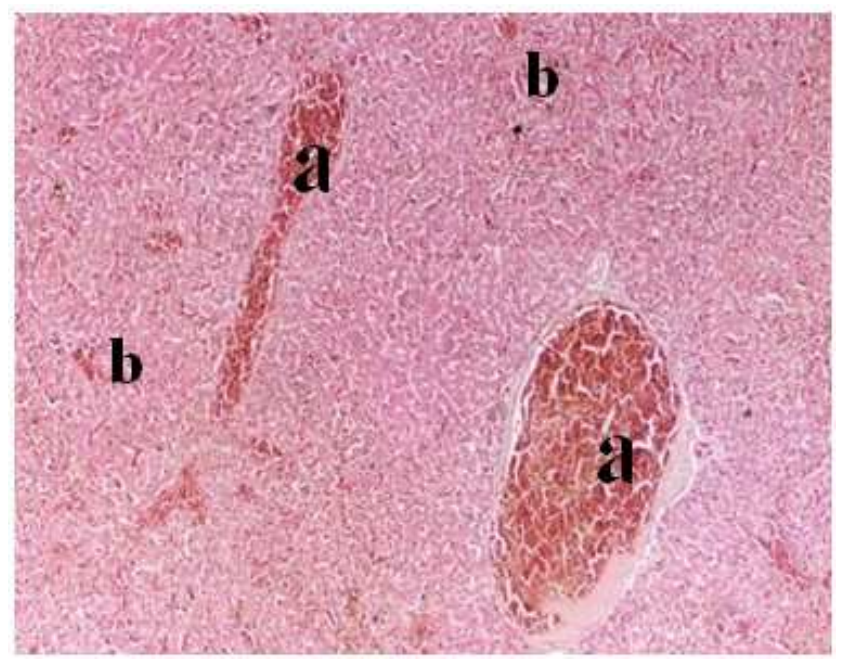

Plate $\boldsymbol{V}$. Photomicrograph of the liver of Japanese quail (Coturnix coturnix japonica) experimentally infected with $10^{6}$ of Salmonella enterica serovar Gallinarum. Note severe congestion (a) and haemorrhages(b). $H \& E . \times 40$.

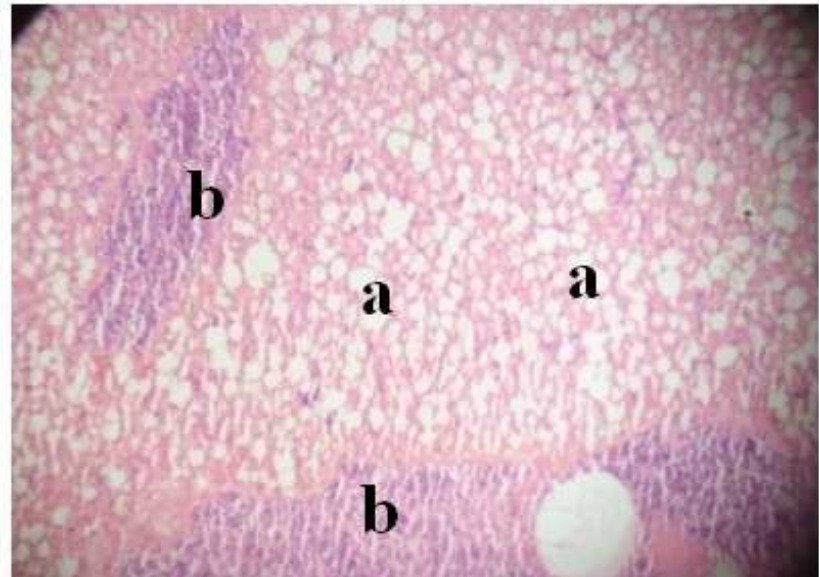

Plate VI. Photomicrograph of the liver of Japanese quail (Coturnix coturnix japonica) experimentally infected with $10^{6}$ of Salmonella enterica serovar Gallinarum. Note generalized vacuolation due to fatty infiltration (a) and cellular infiltration (b). $H \& E . \times 100$.

A mortality rate of $30-35 \%$ was recorded in this study, which is a little lower but still significant as that in chickens (10-93\%) reported by Shivaprasad (1996). The mortality in this study was mostly that of sudden death, suggesting that the infection might have been peracute to acute. The mortality started five days post-infection and persisted tillday twenty.The high mortality recorded in this experiment indicated that Japanese quails are also susceptible to Salmonella enterica serovar Gallinarum similar to the chickens.The gross lesions and histopathological findings observed in Japanese quails (Coturnix coturnix japonica) in this study were consistent with previous studies in chickens ( Garcia et al., 2010). The gross lesions of hepatomegaly, splenomegaly, swollen kidneys, congested liver, lung and ovarian follicle, bronze liver, egg yolk peritonitis, edematous lung and hydroperitoneum (ascites), observed in this study were also similar to those in chickens reported by previous researchers (Beyaz et al., 2010; Garcia et al., 2010). The gross lesions are highly indicative of septicaemic infection. The histopathogical findings (cellular infiltration of the liver and heart, vacuolation of hepatocytes and congested liver and lung) in this study were also similar to previous works in chickens (Hossain et al., 2006; Nwiyi and Omadamiro, 2012).This is the first time these findings were reported in quails in Zaria, Kaduna State, Nigeria to the best of our knowledge.The organism was isolated from the liver, spleen, heart and intestine of the quails at the end of the experiment; implying a septicemic condition.

\section{Conclusion}

This study demonstrates that Salmonella Gallinarum caused a septicaemic disease with distributionof the organism in major organs and characterized by high mortality, congestion and enlargement of various organs in Japanese quails (Coturnixcoturnix japonica). Other pathological findings, such as bronze liver,hepatomegaly, splenomegaly and congested liver, lung and ovarian follicle in this study 
indicated that Salmonella Gallinarum produces a disease similar to that in chickens.

\section{Recommendations}

Vaccinating Japanese quails reared in the country is highly recommended as a preventive measure against fowl typhoid.Farmers keeping quails should adhere to strict biosecurity measures as means of prevention and control of fowl typhoid in quail farm.

\section{References}

[1] Agbaje, M., Davies, R., Oyekunle, M.A., Ojo, O.E., Fasina, F.O.andAkinduti, P.A. (2010). Observation on the occurrence and transmission pattern of Salmonella gallinarum in commercial poultry farms in Ogun State, South Western Nigeria. African Journal of Microbiology Research, 4(9):796800 .

[2] Agrey, S.E., Ankra-Badu, B.A. and Marks, H.L. (2003).Effect of long-term divergent selection on growth characteristic in Japanese quail. Poultry Science, (82): 538- 542.

[3] Beyaz, L., Atasever, A., Aydin, F., Gumusoy, K.S.andAbay, S.(2010). Pathological and clinical findings and tissue distribution of Salmonella gallinarum infection in turkey poults. Turkish Journal of Veterinary and Animal Sciences, 34: 101-110.

[4] Chadfield, M.S., Brown, D.J., Aabo, S., Christensen, J.P. and Olsen, J.E. (2003). Comparison of intestinal invasion and macrophage response of Salmonella gallinarum and other host adapted Salmonella entericaserovars in the avian host. VeterinaryMicrobiology, 92: $49-64$.

[5] Garcia, K.O., Santana, A.M., FreitasNeto, O. C., Berchieri Jr. A. and Fagliari, J. J. (2010). Experimental infection of commercial layers using a Salmonella entericaserovarGallinarum strain: blood serum component and histopathological changes. Brazilian Journal of Veterinary Pathology, 3(2): 111-117.

[6] Haruna, E.S., Musa U., Lombin, L.H., Tat, P.B., Shamaki, P.D. Okewale, P.A. and Molokwu, J.U. (1997). Introduction of quail production in Nigeria. Nigerian Veterinary Journal, 18:104-107.
[7] Hossain, M.S., Chowdhury, E.H., Islam, M.M., Haider, M.G. and Hossain, M.M. (2006). Avian Salmonella infection: isolation and identification of organisms and histopathologicalstudy.Bangladesh Journal of Veterinary Medicine, 4: 7-12.

[8] Huss, D., Poynter, G. and Lansford, R. (2008). Japanese quail (Coturnixcoturnix japonica) as a laboratory animal model. Department of Biology, Biological Imaging Centre, California Institute of Technology, Pasadena. CA. USA. Laboratory Animal(NY),37(11):513-519.

[9] Miles, A. A and Misra, S A. (1938). The estimation of bacterial power of the blood.Journal of Hygiene, 38:732.

[10] National Veterinary Research Institute (2008). Quail production in the tropics: National Veterinary Research Institute, Vom, Nigeria, 75-92.

[11] Nwiyi, P. and Omadamiro, O. (2012). Seroprevalence and Isolation of Chicken Infected with Salmonella: Haematological and Pathological Evaluation. Journal of Animal and Feed Research, 2(6): 483-487.

[12] Oladele, S.B., Enoch, I and Ibrahim, N.D.G. (2008). Changes in histopathology, haematocrit, haemoglobin, haemagglutination inhibition antibody titre and total protein of Japanese quails (Coturnixcoturnix japonica) administered different doses of Newcastle disease virus. Journal of Animal and Veterinary Advances, 7(4):418-424.

[13] Parmer, D.and Davies, R. (2007). Fowl typhoid in small backyard laying flock. The Veterinary Record, 160:348

[14] Popoff, M.Y., Bockemuhl, J. and Gheeshing, L.L. (2003). Antigenic Formulas of the SalmonellaSerovars, 8th revision. WHO Collaborating Centre for Reference and Research on Salmonella. Supplement 2001 (No: 45) to the KauffmannWhite Scheme Research in Microbiology, 154: 173-174.

[15] Saidu, L., Abdu, P.A., Umoh, J.U. and Abdullahi, U.S. (1994). Diseases of indigenous chicken. Bulletin Animal Health Production in Africa, 42: 19-23.

[16] Shivaprasad, H.L. (1996). Pullorum Disease and Fowl Typhoid. Calneck BIN (ed). Disease of poultry .Tenth Edition. Pp 82-96. Iowa State University Press. 